\title{
Canal 9 frente al espejo: gobierno y empresarios en dos momentos de la historia de la televisión argentina (1973 y 1984)
}

\author{
Channel 9 in front of the mirror: government and businessmen in two moments \\ in the history of Argentine television (1973-1984)
}

\author{
Mariana Rosales \\ comunicacionsecu@gmail.com \\ Universidad de Buenos Aires, Argentina \\ Joaquín Sticotti \\ joaquinsticotti@gmail.com \\ Universidad de Buenos Aires, Argentina
}

Recepción: 03 Diciembre 2019

Aprobación: 12 Julio 2020

Publicación: 04 Enero 2021

Cita sugerida: Rosales, M. y Sticotti, J. (2021). Canal 9 frente al espejo: gobierno y empresarios en dos momentos de la historia de la televisión argentina (1973 y 1984). Trabajos y Comunicaciones, (53), e131. https://doi.org/10.24215/23468971e131

\begin{abstract}
Resumen: El presente trabajo se propone, a partir del análisis de dos momentos bisagra para la historia del Canal 9, reflexionar sobre el papel de empresarios y gobiernos en la televisión argentina. La hipótesis principal es que se puede observar un desplazamiento en los roles cumplidos por los funcionarios del Estado y los empresarios ligados a la televisión de 1974 a 1984. Se indagan dos tipos de fuentes: unas que proyectan la imagen que el Canal 9 construía de sí mismo y otras asociadas al contexto estatal y mediático. Luego de analizar cada momento, se integra el análisis en una conclusión que busca remarcar las características de este desplazamiento.
\end{abstract}

Palabras clave: Televisión, Gobierno, Empresarios.

\begin{abstract}
The aim of this work is the analysis of two crucial moments in the history of Channel 9 to show the role of businessmen and governments in Argentine television. The main hypothesis is that a shift can be observed in the roles played by State officials and businessmen linked to television from 1974 to 1984. Two sets of sources are investigated: some project the image that Channel 9 built of itself and others provide contextual information about State and media. After analyzing each moment, the analysis is integrated into a conclusion that seeks to highlight the characteristics and consequences of this shift.
\end{abstract}

Keywords: Television, Government, Businessmen.

\section{INTRODUCCIÓN}

El presente trabajo aborda la historia reciente de la televisión en Argentina. Nuestro enfoque, desde la historia de los medios de comunicación, busca pensar lo que sucede en la pantalla en relación con los diversos actores sociales que se involucran en la producción de los programas, la gestión de los canales, los negocios y los intereses políticos. En este trabajo nos concentramos fundamentalmente en el gobierno y los empresarios del espectáculo, cuyos papeles son centrales en la historia de la televisión latinoamericana. La televisión comienza en Argentina el 17 de octubre de 1951 con la transmisión de un acto político por el día de la lealtad peronista 
(Varela, 2005). En 1958, se licitan a privados las licencias de los canales 9, 11 y 13 de la Ciudad de Buenos Aires. Durante los años 60 las tres grandes networks estadounidenses (ABC, NBC y CBS) desembarcan en el mercado argentino participando de las productoras de programación de los canales privados de la capital (Muraro, 1973). Las cadenas norteamericanas conviven con empresarios locales cuyos roles son centrales en todas las televisiones latinoamericanas (Sinclair, 1999). En este contexto, Canal 9 será el primero de los canales privados en el que los empresarios argentinos le comprarán la participación accionaria a la NBC a fines de 1963. A su vez, luego de la estatización de los canales y sus productoras de programación en 1974, Canal 9 será el primer canal que volverá a manos privadas (y a uno de sus antiguos dueños, Alejandro Romay) en mayo de 1984.

El objetivo principal de este trabajo es analizar dos momentos decisivos de la historia del Canal 9 de la Ciudad de Buenos Aires: el de su estatización entre 1973 y 1974 y el de su reprivatización en 1984. Consideramos que este análisis constituye un aporte respecto al rol de gobiernos y empresarios en un período relevante de la historia de la televisión argentina que ha sido poco explorado por la bibliografía existente (Becerra, 2015; Mastrini, 2005; Mindez, 2001; Muraro, 1987). Realizaremos este análisis a través de dos documentos inéditos que son parte de una colección que la familia de Alejandro Romay donó al Archivo Audiovisual del Instituto de Investigaciones Gino Germani. Estos documentos nos permiten construir una imagen de cómo la productora de programación y el canal de Romay pensaban su rol en estas dos coyunturas decisivas. Como complemento, analizaremos otras fuentes del período que nos permitirán caracterizar un panorama más general sobre el accionar del gobierno y los empresarios de la televisión: leyes, decretos y planes oficiales, pero también, diarios, revistas, y grillas de programación. A su vez, como marco conceptual funcional al análisis empírico, utilizaremos los conceptos de: programación de Raymond Williams (2011), de nacionalismo de Benedict Anderson (1993), de contrato enunciativo de Eliseo Verón (1985) y de televisión interrumpida de Daniel Dayan (1992).

Finalmente, desde la historia política, estamos ante dos momentos profundamente diferentes dado que en el medio se encuentra la dictadura más violenta que tuvo la Argentina y la que más cambió, desde distintos enfoques historiográficos, la economía, la política y la cultura del país (Canelo, 2016; Novaro y Palermo, 2013). Sin embargo, creemos que es importante, asumiendo la perspectiva de la historia de los medios, pensar cómo estas grandes reconfiguraciones no están exentas de algunas líneas de continuidad. Observar el modo en que los empresarios de la televisión y los gobiernos construyen posiciones, asumen roles y dan debates tanto en 1973 y 1974 como en 1984 puede resultar enriquecedor para pensar el devenir de estas posiciones atendiendo a lo que se transforma y a lo que permanece inalterado. Finalmente, aunque no sea el objeto del presente trabajo analizar lo acontecido con los canales gestionados por el Estado durante la última dictadura, consideramos que el análisis de los dos momentos seleccionados puede ser un aporte a la comprensión de lo que se transformó en esos años decisivos de nuestra historia reciente respecto al rol de los empresarios y los gobiernos en relación a los medios de comunicación.

Estructuramos el trabajo en dos partes: en la primera nos ocupamos de reconstruir el proceso de intervención de los canales de la ciudad de Buenos Aires que incluyó al Canal 9 y a la productora Telecenter presidida por Romay entre 1973 y 1974. Para analizar este proceso, nuestra fuente principal será undossier institucional elaborado por la productora. En la segunda parte, nos dedicamos a analizar el proceso de re privatización del Canal 9 en 1984. Para esto, tomaremos como fuente principal un material audiovisual que registra el acto de entrega por parte de funcionarios estatales de la licencia de Canal 9 a Telearte S.A. Finalmente, a modo de cierre, buscaremos caracterizar el desplazamiento operado entre los dos momentos analizados haciendo foco en cómo se transforma el papel de los empresarios y de los gobiernos. Postulamos, a su vez, que esta transformación tendrá un lugar decisivo en el futuro del medio. 


\section{Parte 1: El proceso de nacionalización del Canal 9 entre 1973 y 1974.}

A fines de 1973, la productora Telecenter, encargada de la programación del Canal 9 de la Capital Federal, realiza un "Dossier Institucional" ${ }^{1}$ donde reivindica su rol como promotora de la producción argentina de programas. Aunque no podamos determinar qué circulación tuvo ese dossier sí podemos tomarlo como un documento donde el canal y su productora asociada buscan sintetizar una posición respecto al propio papel en la televisión argentina del pasado, el presente y el futuro. Entre otras cosas, el documento compara porcentajes de programación producida en Argentina en relación con otras productoras, enumera programas realizados y reivindica su rol en los últimos años de historia de la televisión en el país. Finalmente, concluye con la defensa de un modelo mixto de televisión y reivindica su propio papel como empresarios comprometidos con la construcción de un medio nacional.

Las licencias de los canales 9, 11 y 13 de la Ciudad de Buenos Aires habían sido licitadas en condiciones poco transparentes en 1958 durante el gobierno de facto de Pedro Eugenio Aramburu (Mastrini, 2005; Muraro, 1973). La concesión duraba 15 años, venciéndose en ese mismo 1973. La primera resolución gubernamental al respecto es el decreto núm. 1761 del 8 de octubre de 1973, publicado el 16 de octubre de ese año en el Boletín Oficial, donde se afirma la caducidad de las licencias privadas que se encargaban de gestionar los canales 9, 11 y 13 de Buenos Aires. Más tarde, el decreto núm. 340 del 31 de julio de 1974 anuncia la expropiación de los bienes inmuebles y las productoras de programación (26 de agosto de 1974. Boletín Oficial, s.p.). Durante el período en que los canales habían sido gestionados por privados, la televisión se había consolidado como un medio con un lenguaje propio (Varela, 2005), importante para el entretenimiento y cada vez más relevante en el papel de transmitir información. En estas condiciones comienza a discutirse la estatización de los canales y sus productoras de programación que, en la mayoría de los medios de comunicación, es presentada como la "nacionalización de la televisión". Entre el decreto de octubre de 1973 y el de julio de 1974 la cuestión se debate públicamente. Entendemos que la discusión excede el papel del Estado en el asunto e involucra también a empresarios de la televisión que disputan el sentido de lo nacional en el medio más allá de su propiedad privada y su fin comercial. El ejemplo paradigmático que encontramos es el de Alejandro Romay, dueño del Canal 9 y su productora asociada Telecenter.

El discurso nacionalista en los medios de comunicación ligado a su rol de integración de una comunidad puede remontarse al rol del periódico analizado por Benedict Anderson (1993). Similares características a las desarrolladas por Anderson para el periódico pueden atribuirse, en la segunda mitad del siglo XX, a los medios broadcast (radio y televisión). En el caso de Canal 9, el nacionalismo consiste también en una marca identitaria que le permite, desde la compra de la mayor parte del paquete accionario por parte de Romay a fines de 1963, posicionarse en la competencia entre los canales capitalinos como el que mayor cantidad de programación producida en Argentina ofrece. Partiendo del carácter inasible para la investigación histórica que tiene lo que Raymond Williams denomina el flujo, es decir el carácter de secuencia ininterrumpida de lo que se observa en la pantalla, nos concentramos en lo que el mismo autor denomina "tipos de programación" refiriéndose a la distribución de los distintos formatos de programas (2011, p. 105). Canal 9 recurre durante su etapa de gestión privada a símbolos de la tradición nacional (campo, gauchos, costumbrismo) para acentuar su perfil diferente a los históricos líderes de audiencia, el Canal 11 y el Canal 13, que mezclan programas informativos locales con una porción importante de programación extranjera denominada "enlatada". La programación lanzada en 1967 por Canal 9 con programas como El conventillo de la paloma, Simplemente María, etc... puede ser un ejemplo claro de esta identidad forjada en los años previos. ${ }^{2}$ De este modo, el canal va estableciendo un contrato enunciativo (Verón, 1985) con su público que sabe qué tipos de programas va a encontrar en la pantalla de Canal 9.

Será esta identidad la que Canal 9 sacará a relucir en el contexto del debate por la posible estatización de las licencias de los canales de la Capital Federal. La estrategia funcionó de la siguiente forma: si lo que se estaba discutiendo era el carácter nacional de la televisión, Canal 9 debía hacer público su aporte a la construcción 
de una televisión nacional desde su lugar de medio privado y comercial. El dossier institucional producido por Telecenter irá en esta línea.

El dossier comienza con un apartado titulado "Cuando producir fue independizar" que pondera la importancia de la licitación de los canales privados realizada por Aramburu en 1958. Más allá de reconocer la importancia de la medida, el énfasis está puesto en las limitaciones que ofrecía para una verdadera nacionalización de la pantalla:

La medida fue verdaderamente importante, porque sirvió para impulsar el desarrollo de los medios de comunicación, sin embargo, lamentablemente, las limitadas posibilidades que ofrecía en ese momento el mercado publicitario y la falta de equipos humanos no permitieron producir programas nacionales como era de desear (Dossier institucional, p. 1).

Vemos como Canal 9 se presenta a sí mismo como un agente empresarial a favor de la producción local de programación. El problema de la medida, según la narrativa del dossier, está en el carácter dependiente que genera respecto de las networks estadounidenses en cuanto a la compra de contenidos para los canales. Aunque las licencias de explotación de los canales sean otorgadas a empresarios locales, sin recursos humanos ni mercado publicitario, el negocio seguirá quedando en manos de las productoras extranjeras. A continuación, se explicita el quiebre a fines de 1963 a partir de la compra de la mayoría del paquete accionario de Telecenter por parte de la empresa de Romay llamada Compañía Argentina de Televisión:

Es a partir de 1964 cuando la COMPAÑÍA ARGENTINA DE TELEVISIÓN [sic] entiende que producir es independizar. Y entonces, inicia una lenta pero progresiva realización de programas artísticos propios que, en la medida de su buen éxito, le permiten recuperar su poder de decisión (ibid., p. 1).

Es entonces desde el emprendedurismo ligado a la producción de contenidos que los canales van a conquistar un nivel de independencia que les permitirá nacionalizar las pantallas. El apartado cierra con un mensaje entre comillas y en letras mayúsculas que le habla más al presente de 1973 que al breve recorrido histórico repuesto: "PRODUCIR ES LA ÚNICA MANERA DE ASEGURAR LA EXISTENCIA DE LOS CANALES DE TELEVISIÓN PARA LA DECISIÓN ARGENTINA” [sic](ibid., p. 1).

El siguiente apartado del dossier se titula "Cuando producir fue nacionalizar" y comienza afirmando:

Lograda la independencia de la televisión argentina con el desplazamiento de los colosos de la producción internacional como la NBC, CBS y ABC se hizo necesidad perentoria la nacionalización de las pantallas. Era imprescindible instaurar una programación auténticamente argentina limitando en todo lo posible el material foráneo (ibid., p. 2).

A continuación, se muestra un gráfico donde se constata el aumento porcentual de la programación nacional en Canal 9 desde 1964 a 1973: 
FIGURA 1

Gráfico demostrativo de la programación nacional de Canal 9

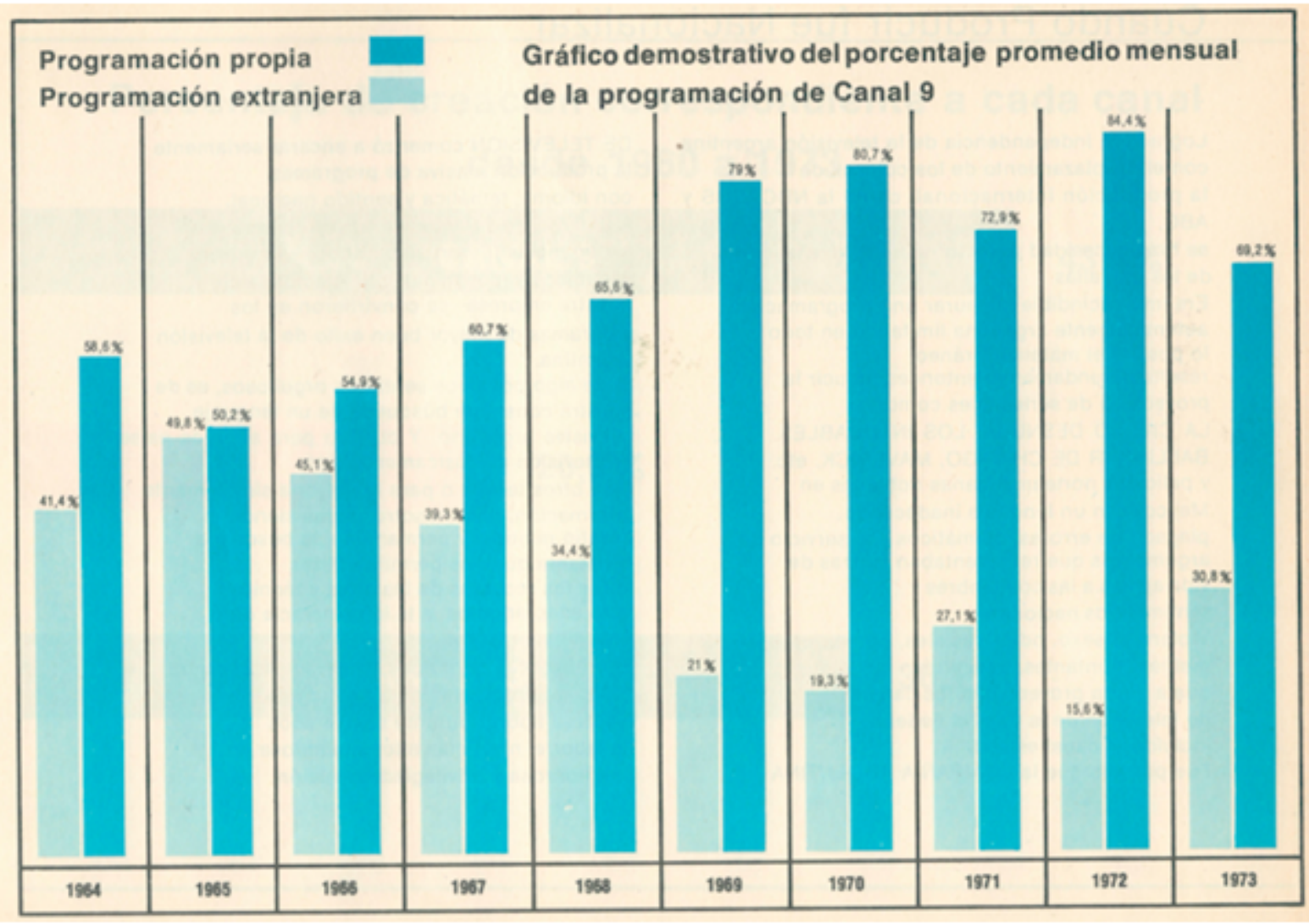

Dossier institucional, p.3

Vemos aquí como el canal hace explícito su compromiso con cierta idea de nacionalización de la televisión. En los términos de la propia narrativa del dossier, Canal 9 sienta la posición de estar involucrado en la nacionalización de la televisión en 1973 y también de haber propiciado la misma desde 1964. Por otro lado, enmarca su labor en las prácticas empresariales destacando el lugar de Telecenter como empresa de producción de contenidos culturales y asume las dificultades, explicitando que buscaron limitar "todo lo posible" el material extranjero, para llevar adelante esta tarea de nacionalización de la pantalla.

Luego de estos apartados, a los que le siguen algunos gráficos comparando la producción de Canal 9 con el resto de los canales de ciudad de Buenos Aires y con algunas televisoras norteamericanas y europeas, el dossier dedica unas palabras a la coyuntura histórica de finales de 1973. Ante la discusión respecto a la posible estatización de la televisión, los empresarios insisten en la defensa de un sistema mixto que incluya la gestión estatal y privada. En su opinión, la nacionalización y la estatización no son sinónimos. Respecto a los problemas que tiene el medio, se establecen responsabilidades ecuánimes:

Así las cosas, si aceptamos que la televisión argentina presenta hoy grandes fallas que hay que corregir todos -particulares y Estado- tenemos en ello gran parte de responsabilidad y todos también estamos citados y obligados a organizar y promover definitivamente una gran televisión nacional (ibid., p. 6).

En esta distribución de responsabilidades se puede leer también el reclamo por no quedarse afuera de la televisión que vendrá. En este sentido el argumento productivista vuelve a ser postulado con vehemencia: "Entonces, como se ha visto, el sistema puede ser estatal, privado, mixto o intermedio pero lo cierto y definitivo es que SIN PRODUCCIÓN PROPIA [sic] cualquiera de ellos dependerá definitivamente de terceros, nacionales o internacionales, careciendo de autonomía y autenticidad" (Ibid., p. 6.). En síntesis, en el 
marco del proceso de nacionalización de la televisión que se discute públicamente entre 1973 y 1974, Canal 9 busca sumar complejidad al debate y posicionarse de cara a la televisión que viene. Distingue la gestión de los canales de la producción de programación y se postula a sí mismo como un actor empresarial comprometido con el desarrollo nacional e independiente del medio.

La estatización de los canales se discute públicamente en el marco de una coyuntura plagada de conflictos políticos ligados fundamentalmente a la interna dentro del movimiento peronista (Franco, 2012). En un relevamiento hemerográfico sobre el debate público respecto al futuro de la televisión entre octubre de 1973 y agosto de 1974 encontramos expresiones en torno al tema en diversas publicaciones del período como el diario Crónica, la revista Gaceta de los espectáculos, dedicada específicamente al cine, la radio y la televisión y El descamisado, revista política de un sector de izquierda del peronismo que dedicó una serie de notas a la problemática de la televisión en diciembre de $1973{ }^{3}$

El 6 de noviembre de 1973 en la Gaceta de los espectáculos se puede observar una publicidad del propio Canal 9 que parece plasmar una parte del discurso desarrollado en el dossier. La publicidad se titula "Nos propusimos crear un canal con estilo argentino pero logramos mucho más". La imagen incluye una foto de la puerta del canal donde se puede ver mucha gente haciendo una fila, más el logo de Canal 9 y un texto que recupera algunos aspectos del dossier institucional:

FIGURA 2

Publicidad de Canal 9 (6 de noviembre de 1973)

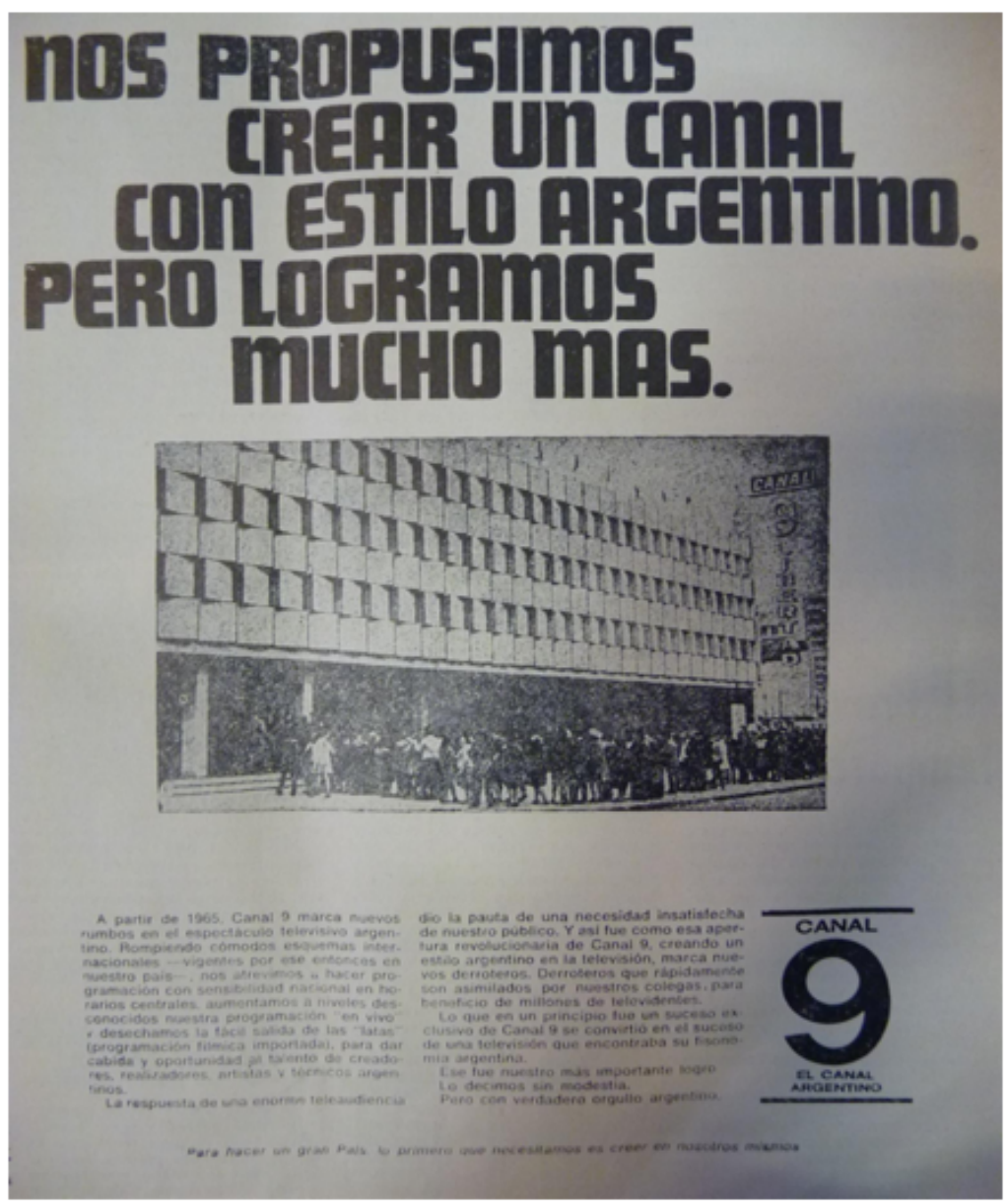

Gaceta de los espectáculos, p. 335. 
Esta publicidad nos aporta una nueva dimensión respecto al discurso del Canal 9 por el interlocutor que presupone. Gaceta de los espectáculos era una publicación orientada a empresarios que participaban del negocio del entretenimiento, como exhibidores cinematográficos, directivos de productoras de programación o publicitarios. Por eso allí el discurso interpela a esos sectores buscando colocarse en una posición de vanguardia en la tarea de nacionalizar la programación. Nuevamente remontándose a la transformación del canal a mediados de los 60, la publicidad afirma: "y así fue como esa apertura revolucionaria de Canal 9, creando un estilo argentino en la televisión, marca nuevos derroteros. Derroteros que rápidamente son asimilados por nuestros colegas para beneficio de millones de televidentes" (figura 2). Complementando esta narrativa con la del dossier vemos como Canal 9 se presenta como el canal y la productora abanderados del estilo argentino no sólo para sus televidentes sino también entre sus colegas. En términos de su propio alegato, su compromiso con la nacionalización de la televisión desde mediados de los 60 le permite a Canal 9 erigirse, ante empresarios del entretenimiento y ante el Estado, como el abanderado de la televisión nacional.

Este discurso iba a ser duramente cuestionado por otros actores políticos expresados, por ejemplo, en la revista Eldescamisado. ${ }^{4}$ En el contexto de la discusión por la estatización de la televisión, se producen una serie de notas dedicadas a los tres canales de la ciudad de Buenos Aires y sus referentes: Alejandro Romay del 9, Héctor Ricardo García del 11 y Goar Mestre del 13. La nota dedicada a Romay se publica el 4 de diciembre de 1973. Allí se menciona a los tres referentes de los canales como: "Estos zares de la televisión (Romay, García y Mestre) pretenden ahora presentarse como peronistas de la primera hora, ante el gobierno y como víctimas del totalitarismo, ante los trabajadores de los canales" (p. 7). La nota busca explicitar los intereses mercantiles de Romay a partir de mencionar sus negocios empresariales más allá de la televisión y, al contrario de lo que plantea Canal 9 en su dossier, destaca el papel de Alejandro Romay, a partir de 1965, en la incorporación de series extranjeras, principalmente norteamericanas, a la pantalla de la televisión argentina. Al mismo tiempo, leído en función del discurso que el canal sostiene en el dossier y en la publicidad analizada, la intención de la nota es mostrar el carácter supuestamente oportunista y poco genuino del discurso nacionalista de Canal 9. La dimensión que la nota de El descamisado nos muestra es como, para ciertos actores del período, el fervor nacionalista de algunos discursos puede ser leído como una impostura que busca acomodarse a una coyuntura política particular dada por el peronismo a cargo del Poder Ejecutivo.

Asimismo, a partir del relevamiento hemerográfico, pudimos observar que el diario Crónica publicó varias notas siguiendo el conflicto respecto a la nacionalización de los canales de televisión, entre octubre de 1973 y julio de 1974. Entre ellas, destacamos las solicitadas tanto de Canal 13 como de Canal 11 en defensa de la instalación de un sistema mixto de televisión. Vemos de esta manera como otros actores se van haciendo eco de la lectura de Canal 9 desde finales de 1973: es inevitable que el Estado comience a participar en el negocio de la televisión, por lo tanto los canales y las productoras privadas de programación deben acomodarse para no quedar completamente fuera del negocio. En junio de 1974, desde la ciudad de Nueva York, Alejandro Romay seguía manteniendo un discurso peronizado en relación al asunto de la nacionalización de los canales. En una nota publicada en Crónica el 14 de junio, afirma: "La iniciativa tomada por el presidente Juan Domingo Perón es una esperanza y abre las puertas de una nueva etapa real de normalización”. Pero a su vez explica que se encuentra en Nueva York para no ser "obligado a acceder" a una demanda del 130\% de aumento de salarios realizada por la comisión interna del sindicato de trabajadores de Canal 9 (Compás de espera en el Canal 9, p. 9). Alejandro Romay se expresa entonces directamente al interior de la interna del peronismo, defendiendo el liderazgo de Perón por encima de lo que denomina "toda una estructura que el gobierno se siente obligado a defender", ya no se trata a esta altura (junio de 1974) de las organizaciones de la izquierda peronista sino sectores sindicales que reclaman un aumento de salario. La profundidad de esta contradicción, expresada en las posiciones del capital y el trabajo, nos vuelve a mostrar cómo Alejandro Romay no renuncia nunca a su identidad empresarial, entendiendo la misma como complementaria con el nacionalismo. 
En el mes de julio de 1974 el gobierno cierra la discusión con la determinación de estatizar la televisión, incluyendo a los canales y a las productoras de programación. A diferencia de Goar Mestre y Héctor Ricardo García que negocian con el Estado indemnizaciones por sus canales expropiados, Alejandro Romay no acepta el pago y lleva la cuestión a la justicia que le terminará devolviendo la licencia en 1984.

Pero como hemos demostrado en esta primera parte, previo a la decisión gubernamental de la estatización, el sentido de una televisión nacional estaba en disputa. Para la mayoría de los actores involucrados no quedaba claro en qué consistiría la estatización: ¿se trataría de estatizar los todos los canales o solamente algunos? ¿qué pasaría con las productoras de programación?. En este contexto, el Dossier Institucional de Telecenter construye un relato que pondera el rol de Canal 9, proyectando una imagen de sí mismo como el canal privado comercial que había hecho sus negocios desde su posición de agente particular del mercado televisivo al tiempo que contribuía a una televisión nacional desde la producción argentina de programación. La narrativa del dossier busca, además, disociar la actividad de la producción de programas de la tarea de gestión de los canales con la aspiración de conservar la propiedad de la productora Telecenter en un contexto de inminente intervención estatal.

\section{Parte 2: 1984, LA PRIMERA PRIVATIZACión de UN CANAL DE TEleVisión EN LA APERTURA DEMOCRÁTICA}

El 25 de octubre de 1983 Bignone firma el decreto núm. 2776 mediante el cual le concede a "Telearte S.A. Empresa de Radio y Televisión (en formación)” la licencia para la prestación del servicio que operará en Canal 9 "al efecto del Plan Nacional de Radiodifusión aprobado el 13 de marzo de 1981" (27 de octubre de 1983, Radiodifusión, Boletín Oficial, p.3). Según esta norma, la licencia se extiende por 15 años, con la facultad de ser prorrogada por 10 años más al momento de su vencimiento, de acuerdo a lo que dicta la ley 22.285 (Poder Ejecutivo, 15 de septiembre de 1980). Así, el grupo empresarial Telearte conformado por Argentino Alejandro Saúl Romay y dos propietarios de dos cadenas de comercios de venta de electrodomésticos, Héctor María Pérez Pícaro y José Osvaldo Scioli, lograba la adjudicación de la licencia de Canal 9, mientras que las concesiones para los canales 11 y 13 quedaban vacantes (Nielsen, 2007).

El decreto 2776 da cuenta que el grupo Telearte S.A. fue el único postulante al llamado a concurso efectuado por el COMFER ${ }^{5}$ para la prestación de servicios de televisión para la estación LS83 TV Canal 9 de Buenos Aires, según se constató el día de apertura de las propuestas, el 2 de septiembre de 1983. Según declaraciones de Alejandro Romay publicadas por la revista Gente el 24 de mayo de 1984, varios candidatos (Acindar, Amalia de Fortabat, Ramón "Palito" Ortega y Goar Mestre) se presentaron a comprar los pliegos de licitación en abril de 1983, pero finalmente ninguno devino en oferente. Según explica en esa nota, la compra del canal tuvo un costo de 4.400 .000 dólares, aunque reconoce que se deberá invertir mucho más que esa cifra para equiparlo y modernizarlo.

Para Alejandro Romay la vuelta a Canal 9 es una reivindicación de la tarea realizada entre 1963 y 1974 , cuyas producciones se intentaron invisibilizar con la eliminación de 2700 tapes de programación: "A ese juicio no quise renunciar", confiesa el empresario a la revista Gente en la misma nota mencionada en el párrafo anterior. Y aunque reconoce que tiempo atrás había declarado que su ciclo en la televisión estaba cumplido, manifiesta que "la televisión no tiene conducción", dejando entrever que los políticos y empresarios que ocupan ese lugar no siguen los criterios que considera válidos o pertinentes. Por ello, y ante la falta de una "generación intermedia", se siente convocado a la misión de dirigir nuevamente un canal (ibid. s/p).

Entre la fecha de dictado del decreto donde se dispone la privatización de Canal 9 a favor de Telearte S.A. y el momento de transferencia de la onda y los inmuebles de Canal 9, a finales de mayo de 1984, observamos que varios elementos de la normativa que regían el sistema de radiodifusión fueron modificados por el flamante gobierno constitucional. 
Diez días después de asumir como presidente, Raúl Alfonsín interviene el COMFER mediante el decreto núm. 235/83. Amparándose en el artículo 86, inciso 10 de la Constitución Nacional donde se establece "que razones de mejor funcionamiento aconsejan efectuar la designación de un funcionario que actúe como delegado normalizador del Comité Federal de Radiodifusión”, el Presidente designa en ese cargo al Dr. Ángel Enrique Lapieza Elli, con atribuciones establecidas por el artículo 98, incisos a) y b) de la ley 22.285 (jueves 22 de diciembre de 1983, Comité Federal de Radiodifusión, Boletín Oficial, p.2). A los pocos meses, Lapieza Elli fallece por causa de un accidente automovilístico y es reemplazado por Pedro Sánchez.

El 13 de abril de 1984 Alfonsín firma el decreto núm. 1151 que suspende la aplicación del Plan Nacional de Radiodifusión (PLANARA) vigente desde marzo de 1981, donde se establecían los pliegos de bases y condiciones generales de los concursos referidos a la adjudicación de licencias de radios y canales de televisión. El artículo 1 del decreto de 1984 aclara que esta medida de suspensión del mencionado plan no perjudicará el "cumplimiento por parte de adjudicatarios de licencias de radiodifusión y de titulares de licencias renovadas, de las obligaciones contraídas en su adjudicación o renovación, y de los derechos adquiridos". Y en el segundo artículo se explicita que quedarían sin efecto aquellos concursos públicos convocados oportunamente por el COMFER y que no hubieran sido objeto de adjudicación por el Poder Ejecutivo hasta esa fecha. En resumen, la suspensión del plan de adjudicación de licencias no debía ser entendida como una "remisión de las obligaciones contraídas" por los adjudicatarios de licencias o de renovación de las mismas, aunque no se harían nuevas convocatorias hasta tanto no se contara con una nueva ley de radiodifusión que reemplazara a la ley vigente, la núm. 22.285 de 1980 (17 de abril de 1984, Radiodifusión, p.3). Con este marco normativo, no habría obstáculos para que Telearte S.A. asumiera la gestión y explotación de Canal 9.

Hacia fines de marzo de 1984, las medidas vinculadas a los medios de comunicación incluidas en la plataforma electoral de la UCR (1983) seguían siendo promesas incumplidas. Así se constata en la publicidad de página entera publicada en la prensa donde el gobierno radical anuncia las metas alcanzadas en los primeros meses de gestión ${ }^{6}$. La derogación de la Ley Nacional de Radiodifusión núm. 22.285, anunciada en la plataforma electoral de la fórmula presidencial de la Unión Cívica Radical, ${ }^{7}$ no figura en la síntesis publicada por el gobierno ocho meses después. Para ese entonces, la Sociedad Argentina Televisora Color (ATC) ya había sido transferida por el decreto no 191/84 desde el Ministerio de Obras y Servicios Públicos hacia la jurisdicción del Ministerio de Educación y Justicia, "de acuerdo con la naturaleza específica de sus funciones y cometidos" (decreto núm. 191, 18 de enero de 1984, Boletín Oficial, p.2). Y dentro de esa estructura ministerial, la Sociedad ATC. LS82 Canal 7 quedaba bajo la órbita de la Secretaría de Cultura en una zona de "administración descentralizada", junto al Fondo Nacional de las Artes, el Instituto Nacional de Cinematografía y Ediciones Culturales Argentinas (decreto núm. 2273/84, 4 de septiembre de 1984, Boletín Oficial, p. 2).

Los otros canales de la ciudad de Buenos Aires estaban en la órbita de la Secretaría de Información Pública (SIP) dependiente de Presidencia de la Nación y contaban con nuevos interventores: libretista Jorge Bellizi en Canal 11, el publicitario Guillermo Meque en el Canal 13 y el periodista Alfredo Garrido desembarca en Canal 9 (Ulanovsky, Sirvén e Itkin, 2011). El flamante interventor de Canal 9 es recordado por Romay (2006) como un ex crítico de cine vinculado con distribuidoras y productoras cinematográficas y ex director de la revista El Heraldo del cine, quien alguna vez había declarado que "la alta cultura no cabe en la televisión. Debe quedar en los talleres literarios, los teatros y los cines".

A partir de 1984 los sectores privados del campo de la comunicación agrupados en la Comisión Empresaria de Medios de Comunicación Independientes (CEMCI) ${ }^{9}$ concentran fuerzas para aumentar su capacidad de demanda al Estado por nuevas medidas legales de implicancia para el sector. El permiso legal para que la gráfica pueda ser adjudicataria de medios electrónicos y las licitaciones postergadas de los medios aún en manos del Estado eran dos de las demandas de mayor importancia y urgencia para los empresarios (Landi, 1987, p. 122).

En sus memorias, Romay confiesa que pensó que al asumir Alfonsín, la privatización de los medios sería inmediata, porque para él era "lo esperable" a partir del regreso a la democracia, "máxime cuando en el caso 
de Canal 9, luego de la licitación, la dictadura firmó el decreto de entrega”. Pero eso no sucedió, en la opinión del empresario, porque Alfonsín "se aferró a los medios en manos del Estado" con una una "política errática" de gestión de los mismos, que expresaba "su desconocimiento, y el de sus colaboradores, acerca de cómo manejarlos” (2006, p. 170). A pesar del estado de endeudamiento de los canales, se demoraba la entrega del 11 y el 9. Entonces Romay inicia otro juicio, esta vez a la "flamante administración alfonsinista" (p. 171) con el que logra finalmente que se efectúe la entrega.

El acto de transferencia de Canal 9 a los nuevos titulares es transmitido por el propio canal en el marco de un programa especial el 24 de mayo de 1984. El documento que vamos a analizar es la grabación de la totalidad de la ceremonia realizada en un estudio de Canal 9, desde las 19 hs., mientras el noticiero estaba al aire desde otro estudio. Si aceptamos como cierto el dato de una fuente periodística sobre la hora de emisión del acto (las 23 hs.), en el horario que dejó vacante el ciclo $A$ solas conducido por Hugo Guerrero Marthineitz (26 de mayo de 1984, Romay, otra vez en el 9. Clarín. $)^{10}$, podemos inferir que este programa especial no fue transmitido en vivo, sino que se grabó a las 19 y se emitió 4 horas más tarde.

Consideramos la ceremonia de entrega de Canal 9 como un caso de "televisión interruptiva" (Dayan, 1992). Es un acontecimiento televisivo definido por su marcada importancia social, su dimensión excepcional y su capacidad de interceptar el flujo televisivo. "Su tiempo escapa a la programación dado que la hace detonar" (p. 158). Dirigidos a la sociedad en su conjunto, este tipo de acontecimientos asumen "una dimensión política" y a la vez "ceremonial" (p. 159), y pueden ser de tipo cíclico (los previstos por calendarios políticos, históricos, religiosos, culturales) o únicos e inesperados. El programa especial del 24 de mayo de 1984 es del segundo orden. Su emisión no fue prevista en la prensa gráfica y ni siquiera anunciada en la grilla de programación televisiva de ese día. Tampoco aparecieron anticipos de la noticia del acto de entrega en los medios gráficos, salvo un par de excepciones: un pequeño recuadro en la sección de espectáculos de La Nación donde se informaba que la "primera privatización de una televisora de la Capital" se haría efectiva con la entrega de LS83 Canal 9 a la empresa de Alejandro Romay el 24 de mayo a las 19 hs. (sábado 19 de mayo de 1984, Canal 9, La Nación Espectáculos, p.1), y una entrevista a Romay publicada en las dos últimas páginas de la edición de la revista Gente que salió a la venta el mismo día de la ceremonia.

A partir de este momento, reconstruiremos el acontecimiento televisivo, describiendo la secuencia de escenas que lo conforman y las actuaciones de sus protagonistas. Todos los textuales referidos pertenecen al audio de la transmisión. En primera instancia, frente a un atril y con la bandera argentina detrás, el locutor y conductor Silvio Soldán da inicio a la ceremonia televisiva anunciando que es un "acto de transferencia de la onda, equipo e instalaciones de LS83 TV Canal 9, Buenos Aires, Argentina" ${ }^{11}$. Luego, el escribano general de gobierno, Natalio Pedro Etchegaray, lee el acta de transferencia. Y explicita que la misma se realiza el 24 de mayo, a las 19 hs., ante la presencia de todas las partes implicadas: en representación del gobierno nacional, los funcionarios Emilio Gibaja (titular de la SIP), Pedro Raúl Sánchez (delegado normalizador del COMFER), Alfredo Miguel Pascual Garrido (interventor de la televisora), y los empresarios socios de Telearte S.A., sociedad a la que le ha sido adjudicada la licencia: ${ }^{12}$ Argentino Alejandro Saúl Romay (presidente), José Osvaldo Scioli (vicepresidente $1^{\circ}$ ) y Héctor María Pérez Pícaro (vicepresidente $2^{\circ}$ ). 
FIGURA 3

Acta de transferencia de Canal 9 (24 de mayo de 1984).

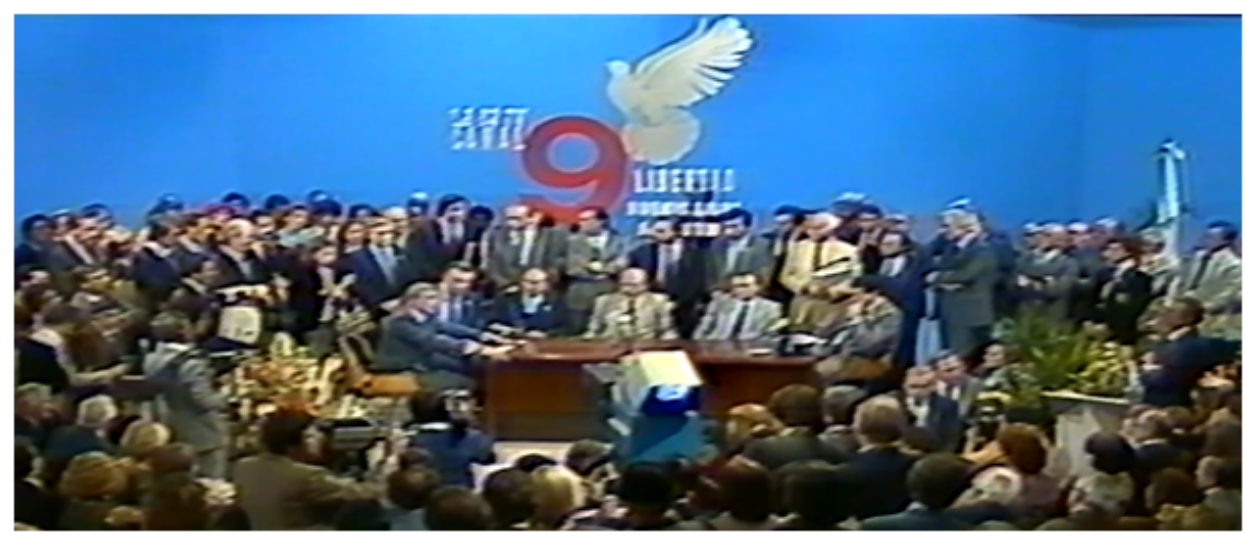

Fuente: Archivo Audiovisual IIGG.

El estudio de televisión está colmado de público, sentado y de pie. Se constata la presencia de corresponsales de otros medios de prensa, radiales y gráficos. La escenografía está compuesta por un fondo celeste con el logo del canal en dos colores, el número 9 en rojo y la tipografía y la paloma en color blanco. En el centro de la escena, los empresarios de Telearte S.A. y las autoridades del gobierno nacional están sentados alrededor de una mesa. Detrás de ellos, entre las muchas personas paradas, podemos identificar a Daniel Scioli, hijo de uno de los socios de la empresa adjudicataria. Tres cámaras cubren el hecho: una fija ubicada frente a la mesa de funcionarios y empresarios, que tomará sus rostros y ademanes en detalle; otra desde el escenario mira de frente al auditorio y de las subjetivas desde la mirada de Romay hacia los funcionarios en el momento de sus discursos, y una tercera que muestra la magnitud del acontecimiento con un plano general.

Mientras el escribano lee el acta, las imágenes en primer plano destacan a los miembros del sistema de estrellas presentes entre el público invitado: María Concepción César, Carlos Calvo, Jorge Barreiro, Leonor Benedetto, Jorge Jacobson, Donald, Marta González, Tincho Zabala. MoriaCasán, Abel Santa Cruz, Alberto Migré son algunas de las figuras del ambiente artístico (entre los numerosos actores y actrices, directores, autores, periodistas, cantantes, escenógrafos) que se suman a los técnicos y ejecutivos del canal, todos señalados por Romay como amigos y miembros de la gran familia del nuevo Canal 9.

Siendo las 19:40 el escribano da por finalizado el acto que lo tuvo como protagonista ${ }^{13}$ e invita al Sr. Scioli a entregar al interventor saliente el cheque a nombre de la dirección general de la SIP por pesos 64.146.012, equivalente al 30\% de la oferta económica. Inmediatamente, Gibaja, Sánchez y Garrido (con gestos de seriedad) y los integrantes de Telearte S.A. (sonrientes) firman el "acta de documentación de transferencia de la LS83 TV Canal 9 a su nuevo permisionario, la empresa privada TelearteS.A .”, textuales palabras del relato del locutor Soldán.

De todos los funcionarios, Garrido es el que tiene una expresión más relajada, hasta esboza una mueca sonriente, y es el que inaugura la ronda de discursos con su balance de gestión. Sostiene que cuando tomaron el mando el 6 de enero de ese año (1984), tan sólo 4 meses y 16 días atrás, encontraron el canal en una "profunda crisis, desmantelado y sin gente que tuviera la posibilidad de expresarse (...) con una pantalla sin posibilidades de contacto con el público". La intención, agrega Garrido, fue hacer una televisión "con inquietudes, de información, de formación, de entretenimiento, de vehículo hacia la cultura y hacia el arte" pensando en "los jóvenes" (a los que señala como protagonistas del destino electoral y al mismo tiempo tan ausentes en el espectro de la televisión), en "la gente" (necesitada de mantener un vínculo con el mundo para 
sobrellevar la soledad) y en "los chicos". Lo fundamental era "poner la fábrica en marcha”, y para ello se abrió un espacio "al espíritu creativo" del personal de la emisora para que pudiera trabajar, siempre invocando a la "responsabilidad individual". Con satisfacción afirma que la respuesta ha sido "altamente extraordinaria" y que al momento de la entrega del canal a manos privadas según lo exige el espíritu de la ley "la fábrica está en marcha" con un futuro muy promisorio ${ }^{14}$. "No es lecho de rosas donde están, creo que le hemos sacado algunas espinas en su camino (...)", expresa con orgullo.

Luego de la entusiasta presentación de Garrido, el Dr. Milo Gibaja (así es presentado por Soldán) lee su discurso. Al inicio explica que con este acto el gobierno nacional demuestra una vez más su "irrevocable decisión de someterse a las leyes nacionales y al imperio de la justicia”, y por ello la resolución respecto del Canal 9 reafirma la "continuidad jurídica del Estado quien pone esta casa en manos de sus nuevos permisionarios que han ganado la licitación correspondiente". Destaca el acto como un "hecho fundamental en la política de comunicaciones del gobierno democrático". Al respecto explica que esta primera privatización de una televisora en la ciudad de Buenos Aires luego de diez años de anuladas las concesiones, donde se entrega la emisora a personas "ya consustanciadas" con ella, debe ser interpretada como un "estilo de comunicación pluralista y de espíritu democrático" que refleja la "vocación de la coexistencia de los medios públicos y privados a los que podría agregarse en el futuro alguna otra variedad jurídica”.

Luego, Gibaja enuncia una serie de definiciones sobre el sistema de medios y el rol de la televisión en esta nueva etapa democrática. En referencia al primero de los temas, señala que la consolidación del "pluralismo en los medios" (al que califica como "una tradición" en la Argentina) permitirá "plena creatividad" por un lado y competencia por el otro. Su gobierno, advierte, "no impone criterios ni dicta normas", sino que espera que la empresa adjudicataria comprenda el "concepto republicano, ético y constructivo en la política de difusión" en virtud de "calidad de la oferta y respeto a los espectadores". Gibaja define claramente el rol del Estado en el modelo de comunicación: “debe ser partícipe (...) pero de ninguna manera excluyente”. Es evidente la transformación del papel del Estado en relación con lo que sucedía entre 1973 y 1974.

Sobre el rol de la televisión, el Secretario de Información Pública califica al medio televisivo como el "más poderoso instrumento de comunicación y acercamiento entre los hombres de esta era", a pesar de los posibles aspectos negativos que se le adjudican, ligados a la homogeneización en la mediocridad y su capacidad evasiva e inhibitoria del pensamiento reflexivo de la audiencia. Y por ende destaca la necesidad de fortalecer la concepción ética de la televisión para la democracia, que a su parecer, debería exhibir "la unidad en la diversidad, el total paisaje físico y espiritual de la patria, sus hombres y sus mujeres" y ser "fiel contribuyente a una confrontación de ideas siempre indispensable". En el discurso del funcionario, la televisión tiene como finalidad servir al entretenimiento (ligado al "goce espiritual"), a la información "sin prejuicios ni condicionamientos ideológicos" y a la cultura, "lejos de sofisticaciones elitistas, atendiendo al servicio de la instrucción pública, del acceso al conocimiento, a la divulgación del arte".

Dueño del discurso más breve y con gesto más serio y adusto que los otros funcionarios, Pedro Sánchez (delegado normalizador del COMFER) se presenta como el representante "del Comité Federal de la Comunicación Democrática”. En su consideración, la libertad carente de responsabilidad deviene en abuso y como tal puede convertirse en el principal conspirador de la sociedad democrática. Por ello, sostiene que la construcción de un sistema comunicacional "al servicio exclusivo y excluyente de la consolidación democrática y republicana” sólo será posible a partir de la práctica de la responsabilidad en la libertad. El desafío del organismo que preside es establecer y consolidar "una comunicación democrática y pluralista para una sociedad de iguales características en la cual debemos quedarnos para siempre".

Luego de los funcionarios, que hablaron en representación del gobierno que los ha designado, le toca el turno a Alejandro Romay, quien es presentado por Silvio Soldán con el título de presidente y director general de Telearte. Sus palabras cierran el acto. El empresario tiene una posición privilegiada en el orden de los discursos que le permitirá referirse a las declaraciones de los anteriores oradores, mediante observaciones e interpelaciones. 
FIGURA 4

Discurso de Alejandro Romay en el acto de transferencia de Canal 9 (24 de mayo de 1984).

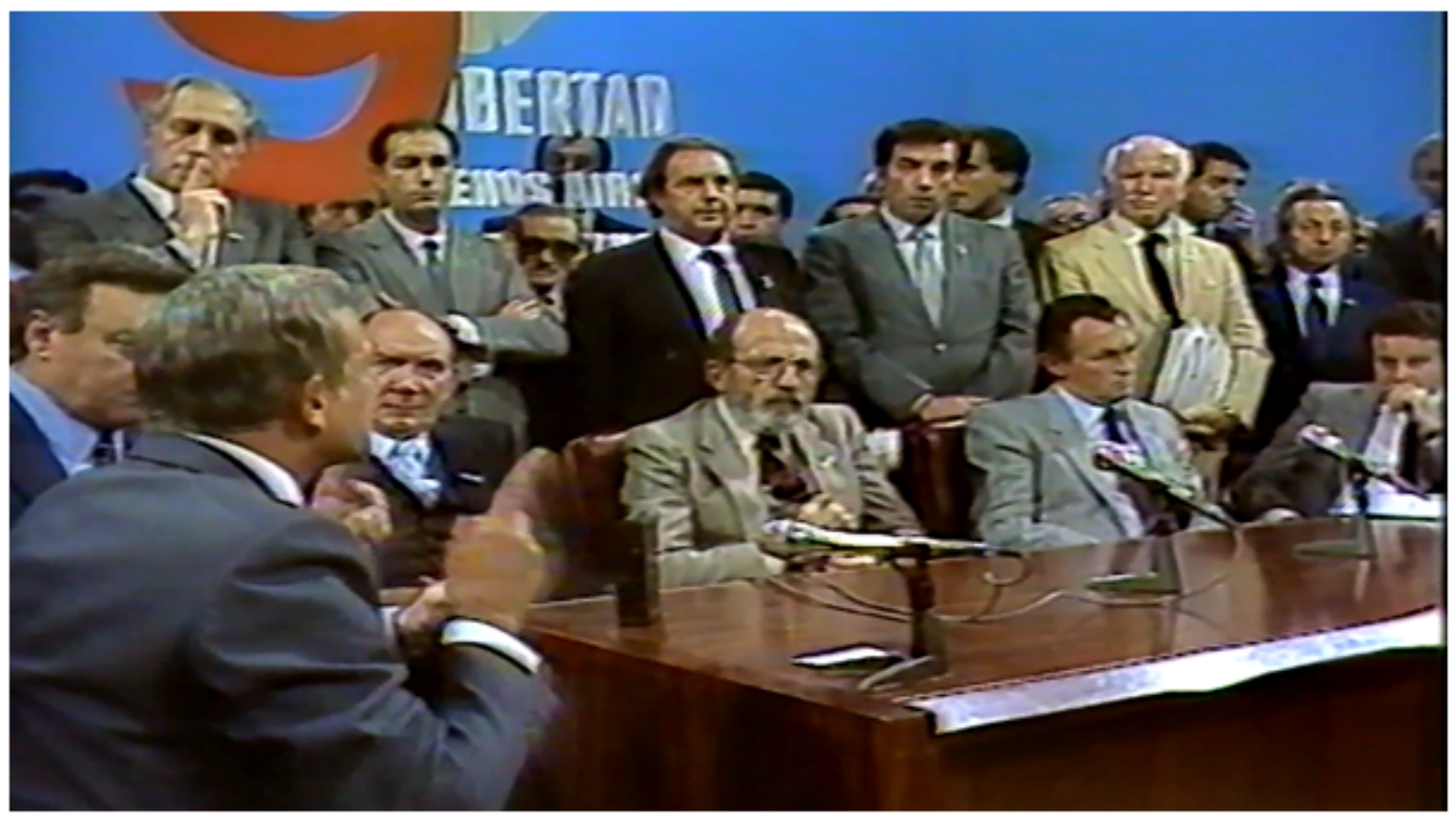

Fuente: Archivo Audiovisual IIGG.

En primer lugar, Romay intenta establecer una definición del acto de adjudicación que se está desarrollando en la televisión. Niega que se trate de una devolución ni de "ningún acto generoso", como circuló públicamente, aunque confiesa que el concepto de devolución lo "llena de orgullo" si se puede interpretar que todos los medios leían este hecho como reivindicatorio de aquel acto "arbitrario y brutal" que se practicó a "través de los sindicatos” en la medida que no observaron los principios de la república (aplausos del público). Y retoma las apreciaciones del Dr. Gibaja para reafirmar que ese acto se trata simplemente del cumplimiento por parte de un gobierno democrático de "una orden judicial proveniente de un decreto" que resolvió una "larga licitación" en el marco de una ley de radiodifusión que ya llevaba tres años de vigencia "sin ninguna voz que la criticara o impugnara". En palabras de Romay, se trata de la culminación de "un acto de compraventa" que corresponde a "una administración republicana" donde "un grupo de empresarios argentinos disponen con fe y con esperanzado anhelo invertir en el país".

Luego de establecer una definición del hecho consumado el 24 de mayo de 1984, el titular de Telearte, nuevamente al frente de Canal 9, interpela a los funcionarios presentes con reclamos, llamados de atención y hasta algunas burlas sobre sus discursos. Alejandro Romay le pide al titular de la SIP que no cometa los mismos errores de otros funcionarios de gobiernos tanto militares como civiles, de considerar a los medios que están en poder del Estado "precariamente pueden ser privatizados, le pertenecen, y entonces ver en la actividad privada competidores rabiosos a los que hay que oponerse, perseguir y sancionar continuamente". Con un tono pedagógico les explica a los funcionarios y al foro en general que a nivel internacional hay un consenso sobre que los Estados que reciben las ondas de radiodifusión no deben "necesariamente actuar en ellas con un sentido monopólico", por el contrario, deben entregarlos a terceros, "subsidiarios del Estado" para "que actúen en forma personal corriendo todos los riesgos". En la nota de Gente del 24 de mayo de 1984, se leen declaraciones de Romay que ratifican y profundizan esta parte de su discurso. Allí expresa que una vez que el gobierno defina cuál será el canal estatal, único por su carácter "educativo" y por estar "al margen del campo publicitario", el secretario Gibaja debería designar una "comisión administradora eventual de los 
medios de comunicación que deben ser privatizados lo más rápido posible". En su opinión, "la SIP no debe ver al Canal 9 como competidor".

Las apreciaciones de Romay en la ceremonia televisiva explicitan su postura sobre el modelo mixto para el sistema de medios. "Los medios en manos del Estado se convierten en herramientas óxidas [sic] que no alcanzan a cumplir su cometido, por eso, realmente el pedido de una rápida privatización". Y en consideración de Romay, la entrega de Canal 9 Libertad [sic] a sus titulares es el primer paso hacia ese tipo de sistema que por ahora es un "anhelo" y que le pide a los funcionarios Gibaja y Sánchez que el gobierno dé continuidad a esta tendencia.

Al delegado normalizador del COMFER le exige reglas de juego claras y precisas por parte del Estado, para evitar acciones arbitrarias "en desmedro de los agentes privados". Y argumenta su pedido soslayando que ante la ausencia de límites la libertad deviene en "libertinaje" y por tal motivo es responsabilidad y facultad del Estado medir los límites en "reglas justas y en principios de equidad". Y al respecto, manifiesta: "cuando el Estado, administrador de las ondas no pague los impuestos yo le sugiero que usted no nos cobre los impuestos a nosotros".

En el marco de los reclamos a los funcionarios por un ambiente justo para desarrollar su tarea creativa, el empresario reivindica a la figura de Pedro Eugenio Aramburu. "La arbitrariedad del Estado no empezó hace diez años", le explica Alejandro Romay a Emilio Gibaja, y otra vez en un tono pedagógico recupera la figura de la Dra. Alicia Moreau de Justo, a quien presenta como la presidenta del Consejo Consultivo de la Revolución Libertadora, por su gesto de pedirle al país y a "su presidente de facto" que "de inmediato desmantelara los órganos de represión que tenía el Estado”. El Estado tuvo miedo, asegura Romay, pero sin embargo, un hombre "que por encima de sí vestía traje militar o traje de civil" (se lo ve a Gibaja muy serio, que mira el piso) (...) un argentino que antes de renunciar quiso dar principio a esa privatización (...) el señor Pedro Eugenio Aramburu" quien efectuó la licitación de 18 emisoras [aplausos].

A lo largo de su discurso, Alejandro Romay se presenta como más experto e idóneo que los mismos funcionarios del área, su larga experiencia en el campo de la televisión le ha otorgado una experticia que lo legitima en su posición. "Mi estimado Garrido", así se dirige al funcionario, "la televisión no es hija para nada de los diarios" sino que "nace de la coyuntura de dos vertientes, el teatro fundamental hacedor de emociones y la radiotelefonía, creadora de imaginaciones" (aplausos). En referencia a la demanda de televisión cultural esbozada por el interventor saliente en su alocución, el empresario advierte que la televisión comercial debe ser una televisión de servicio, y en este rol debe servir a todos los estamentos sociales sin descartar a "ningún" sector social. "¿Cómo no complacer a esos sectores que bajan del andamio y van a sus casas después de 12-14 horas de trabajo [aplausos] para no darle un programa que está pidiendo?”, expresa Romay. Y al respecto, agrega que estos sectores requieren "catarsis" para "descargar sus emociones" y la televisión es el elemento que les permite "evadirse de un sueldo miserable" y de las condiciones "infrahumanas" que vive una clase social "muy baja del pueblo argentino". Más adelante, el empresario asume que su desafío es lograr una "televisión creativa, dinámica, montada sobre las mutaciones de las apetencias populares".

Las definiciones de Romay en pos de destacar la producción nacional del medio televisivo son de suma importancia para nuestro trabajo. En relación a la futura programación de Canal 9, anuncia que van a volver a una televisión "auténticamente nacional", y que "otra vez" el "100\% de la programación" será "en vivo" (es vitoreado y aplaudido por el público presente). Está claro que se trata de una exageración ya que hasta ese momento ningún canal llegó a cubrir la totalidad de la grilla con programación de origen nacional. Incluso, Canal 9 superaría en 1985 y 1986 los porcentajes de programación "enlatada" que tenía a principios de los setenta. ${ }^{15}$ Estos datos entran en contradicción con las declaraciones de advertencia al poder público que hace el empresario en 1984: "no aceptaremos de ninguna manera" que nos digan "que es mucho más barato, más intelectual y de mejor aporte una serie rusa o americana o una película francesa (...) económicamente no podemos compararnos con ellos, actuaremos dentro de los límites que nos da nuestro desarrollo y el pueblo nos va a entender". En su libro de memorias (2006), Alejandro Romay señala que en su discurso del 24 de 
mayo de 1984 dejó en claro que una emisora de televisión debe brindar entretenimiento, pero al mismo tiempo ese entretenimiento debe tener un fuerte contenido popular y con raíz nacional (p. 171).

Hacia el final de su extensa alocución, Alejandro Romay interpela nuevamente a Alfredo Garrido, cuestionando los datos del informe financiero del canal brindados por el interventor saliente. En otro momento ya lo había relativizado cuando a propósito de la demora en alcanzar un vaso de agua había dicho "evidentemente no están dadas las condiciones de producir ningún programa". Esta vez, contrapone las cifras de Garrido sobre las futuras ganancias de la empresa adjudicataria con los datos de sus ejecutivos que define como "meticulosos". Y concluye que de los 400.000 dólares de ganancias previstos por el funcionario saliente, tiene el 50\% de descuento, y de la otra cifra hay que descontar aún los impuestos y el pago al COMFER, con lo cual las pérdidas serían del orden de los “35 millones de pesos que representan 500.000 dólares”. Se escuchan aplausos y risas de parte del público. Garrido, tenso, esboza forzosamente una media sonrisa mientras niega con su cabeza lo dicho por Romay. "Esto es para los diarios" dice el empresario destacando su posición de experto. Y para finalizar confiesa: "he hablado mucho, me perdonan, ustedes saben que me gusta hablar y sobre todo con los amigos". Luego de los aplausos, el empresario despide a los funcionarios y saluda a los amigos mientras una cortina musical apela a la emoción con un tono triunfal. La paloma blanca del logo del nuevo Canal 9 junto a la bandera argentina es la última imagen de la ceremonia que registra el documento analizado.

\section{Conclusiones}

Para concluir, nos interesa poner en diálogo ambos momentos históricos a partir de reflexionar sobre el papel de los gobiernos y los empresarios.

Entre el discurso empresarial asumido por Canal 9-Telecenter en 1973 y por Alejandro Romay en persona en 1984 puede llamar la atención el desplazamiento de reivindicar a Juan Domingo Perón en 1974 y a Pedro Eugenio Aramburu en 1984. Entendemos que esa flagrante contradicción política expresa algo más: una búsqueda de autonomización del campo empresarial. Estaba claro que la peronización de Romay en 1973-1974 era mucho más pragmática que ideológica, así como está claro que la reivindicación de Aramburu se ciñe a su voluntad de abrir a la explotación privada las licencias de los canales en la década del 50 y no a una adhesión plena a los valores de la autodenominada Revolución Libertadora.

En la cuestión de la producción de programación, el discurso empresarial de Alejandro Romay presenta continuidad. La misma consiste en reivindicar su rol como productor de programas de televisión, pero también teatral y radial. Entendemos que este rol le permite consolidar su lugar de preeminencia en relación con el starsystem local al que convoca en 1984 al acto de adjudicación de la licencia de Canal 9. Se trata de una alianza que no es menor pensando en el protagonismo de estos actores sociales en el medio televisivo. Se pueden esgrimir, como afirmamos anteriormente, argumentos para relativizar sus afirmaciones en torno a una producción " $100 \%$ nacional” observando las grillas de Canal 9 pero debemos reconocer su constancia en la reivindicación de la programación nacional basada en el trabajo de autores, realizadores y actores locales.

Pero el punto que nos resulta más relevante es la naturaleza del desplazamiento de las posiciones asumidas por los gobiernos y los empresarios de la televisión entre el primero y el segundo de los momentos analizados en el presente trabajo. Entendemos que la figura de Alejandro Romay es sintomática de este proceso.

En 1973-1974 el discurso de Canal 9-Telecenter es defensivo. A medida que van pasando los meses, se va haciendo más evidente que el Estado se va a quedar con una parte o con todo el negocio de la televisión y se hace necesario adaptar el discurso buscando reservarse un lugar en el futuro modelo mediático. De allí, la particular adhesión de Romay al discurso peronista, con sus evidentes contradicciones denunciadas por $E l$ descamisado. El empresario se repliega y pretende conservar, al menos, su productora de contenidos ante el Estado que se impone como administrador de los canales de televisión. A mediados de 1974, su derrota será evidente y quedará por fuera del negocio televisivo. El Estado parece no solo reclamar la potestad de regular el 
funcionamiento de la televisión sino también tener la capacidad de excluir a actores empresariales del sistema mediático.

En 1984 el discurso de Alejandro Romay es victorioso y ofensivo. En el transcurso de la televisación del acto de traspaso de la onda se encuentran presentes tanto Romay y sus socios, como los funcionarios del Estado. No solamente Romay tiene la última palabra sino que su discurso se extiende mucho más que el de los funcionarios estatales. Se ocupa de dejar en claro que él, como empresario, es el más capacitado para llevar adelante el negocio televisivo dejando incluso en evidencia al interventor Alfredo Garrido por su discurso previo en cuanto a la imprecisión de sus afirmaciones sobre el estado financiero del canal. En este acto, la legitimidad del Estado en la gestión del campo mediático es fuertemente cuestionada y los empresarios, encabezados por Romay, le disputan su posición de único actor autorizado desde un supuesto mayor conocimiento y experiencia en los medios de comunicación, incluso demandando que las privatizaciones continúen. La reivindicación de lo realizado por Aramburu se puede leer en la misma línea: el Estado debería promover la actividad privada en el manejo de los medios y restringir su rol a la regulación del sistema.

Esta situación deja en evidencia un cambio en la relación de fuerzas entre el Estado y los empresarios que recién está comenzando. La privatización de Canal 9 fue la primera de la década. Luego vendrían, en 1989, las de Canal 11 y Canal 13. Para las mismas, se derogaría también el decreto que impedía a las empresas ligadas a los medios gráficos hacerse de licencias de canales de televisión. Entre 1973 y 1984 hay un desplazamiento desde una actitud defensiva hacia una actitud ofensiva de los empresarios de medios en relación al Estado. Los años inmediatamente posteriores demostrarían la profundización de este proceso.

\section{REFERENCIAS BIBLIOGRÁFICAS:}

Anderson, B. (1993). Comunidades imaginadas. Reflexiones sobre el origen y la difusión del nacionalismo. México: FCE. Becerra, M. (2015). De la concentración a la convergencia: politicas de medios en Argentina y en América Latina. Buenos Aires: Paidós.

Canelo, P. (2016). La politica secreta de la última dictadura argentina (1976-1983). Buenos Aires: Edhasa.

Dayan, D. (1992). Televisión interruptiva, entre espectáculo y comunicación. En Ferry J.M., D. Wolton et al. El nuevo espacio público (pp. 58-170). Barcelona: Gedisa.

Franco, M. (2012). Un enemigo para la nación. Orden interno, violencia y "subversión", 1973-1976. Buenos Aires: FCE.

Landi, O. (1987). Medios, procesos culturales y sistema político. En Landi, O (Ed.). Medios, transformación cultural y politica. Buenos Aires: Legasa.

Mastrini, G. (Ed.) (2005). Mucho ruido y pocas leyes. Economia y políticas de comunicación en la Argentina (1920-2004). Buenos Aires: La Crujía.

Mindez, L. (2001). Canal 7: medio siglo perdido. La historia del Estado argentino y su estación de televisión. Buenos Aires: Ediciones Ciccus.

Muraro, H. (1973). La manija II. Los dueños de la televisión argentina. Crisis, número 3, 52-59.

Muraro, H. (1974). Neocapitalismo y comunicación de masas. Buenos Aires: Eudeba.

Muraro, H. (1987). La comunicacio\#n masiva durante la dictadura militar y la transicio\#ndemocra\#tica en la Argentina, 1973-1986. En Landi, O (Ed.), Medios, transformación cultural y politica. Buenos Aires: Legasa

Nielsen, J. (2007). La magia de la televisión argentina. Cierta historia documentada 4. Buenos Aires: Ediciones El Jilguero.

Novaro, M. y Palermo, V. (2003). La dictadura militar 1976/1983. Buenos Aires: Paidós.

Romay, Alejandro (2006). MemoriZAR. Buenos Aires: Tiempos Editorial.

Sinclair, J. (1999). Latin American television. A global view. Nueva York: Oxford University Press.

Slipak, D. (2015). Las revistas montoneras. cómo la organización construyó su identidad a través de sus publicaciones. Buenos Aires: Siglo XXI. 
Sticotti, J. (2020). La televisión nacional, comienzo contingente de una experiencia perdurable: el proceso de estatización de los canales de Buenos Aires (1973-1974). En Nuevo Mundo, Mundos Nuevos, Sección: Cuestiones de Tiempo Presente. Puesto en línea el 24 de febrero del 2020. Disponible en: https://journals.openedition.or $\mathrm{g} /$ nuevomundo/79661

Varela, M. (2005). La televisión criolla. Desde sus inicios hasta la llegada del hombre a la luna 1951-1969. Buenos Aires: Edhasa.

Verón, E. (1985). El análisis del "Contrato de Lectura”, un nuevo método para los estudios de posicionamiento de los soportes de los media. En Les Medias: Experiences, recherches actuelles, aplications. París: IREP.

Ulanovsky, C., Sirvén, P., e Itkin, S. (2011). Estamos en el aire. Buenos Aires: Emecé.

Williams, R. (2011). Televisión. Tecnología y forma cultural. Buenos Aires: Paidós.

\section{NORMAS:}

Decretos del Poder Ejecutivo Nacional (1983 y 1984), Boletin Oficial, recuperados de https://www.boletinoficial.go b.ar/busquedaAvanzada/primera

Decretos del Poder Ejecutivo Nacional (1973 y 1974), Boletín Oficial, recuperados del Fondo Archivo Histórico de la Justicia Militar, sección Consejo Supremo de las Fuerzas Armadas en el Archivo General de la Nación, sección Archivo Intermedio.

\section{Documentos ANALIZADOs:}

Compañía Argentina de Televisión, Telecenter S.A., Canal 9 L.S 83 (1973). Dossier institucional.

Canal 9 (Productor). (1984). Acta de entrega Canal 91985 [sic] [documento audiovisual].

Ambos documentos fueron consultados en el Archivo Audiovisual del Instituto Gino Germani (AAIIGG). Este material integra la Colección Romay, donación de la familia del empresario Alejandro Romay al Instituto de Investigaciones Gino Germani, FSOC-UBA.

\section{Notas}

1 Tomamos el lenguaje de la propia fuente tal como la encontramos. La colección completa forma parte del patrimonio del Archivo Audiovisual del IIGG (FSOC-UBA) y es de consulta pública.

2 Para más información sobre la programación de este año puede verse la muestra realizada en la Expo IIGG 2018 por los autores del presente trabajo. La programación se encuentra disponible en: http://iigg.sociales.uba.ar/2018/09/01/ expo-iigg-3/

3 Para profundizar en el debate público sobre la estatización de los canales 9, 11 y 13 en los medios gráficos se puede ver Sticotti, J. (2020).

4 La revista dirigida por Ricardo Grassi era una publicación semanal ligada a la agrupación Montoneros donde todas las notas se publicaron sin firma (Slipak, 2016). La revista se publicó entre 1973 y 1974 coincidiendo con el período en que se discutía el futuro de la televisión.

5 En cumplimiento de la resolución núm. 601 del 26 de octubre de 1982.

6 Según consta en esa pieza publicitaria, no sólo no se habían realizado sino que tampoco estaban "en marcha” las consignas de la plataforma que contemplaban: 1) la creación de tres sistemas para la explotación de la radio y la televisión - uno reservado al Estado, otro para la gestión privada y un tercero en manos de un "Ente autónomo de derecho público no gubernamental" al cual se incorporarían "los medios intervenidos por el Estado"-; 2) la conformación de una comisión bicameral permanente de radio y televisión; y 3) la integración al Sistema de Radio y Televisión de los programas de Educación a distancia. (30 de marzo de 1984. 100 medidas para que su vida cambie. Diario Popular, p.5).

7 Al respecto, véase nota en La Nación (31 de julio de 1983. Campaña electoral, p.14).

8 En Estamos en el aire, la investigación periodística sobre la historia de la televisión argentina de la que es co-autor junto a Carlos Ulanovsky y Silvia Itkin, Pablo Sirvén hace mención a esta frase de Garrido en los mismos términos que usa Romay en su libro (2011, p. 456). 
9 Esta cámara estaba integrada por las asociaciones de empresarios de todos los medios: Asociación Argentina de Editores de Revistas (AAER), Asociación de Diarios del Interior de la Rep. Argentina (ADIRA), Asociación de editores de diarios de la CABA (ADEBA), Asociación de Radiodifusoras Privadas Argentinas (ARPA) y Asociación de Teleradiodifusoras Argentinas (ATA).

$10 \mathrm{La}$ información brindada por la grilla televisiva del 25 de mayo confirma que el ciclo de Martinheitz había cesado en la programación del canal, ya que en el espacio de las 23 hs. figuraba la leyenda "programa a designar" (25 de mayo de 1984, Clarín Espectáculos. p 3).

11 Documento audiovisual Acto de entrega Canal 91985 [sic] disponible en el Archivo Audiovisual del Instituto Gino Germani (AAIIGG). Este material integra la "Colección Romay”, donación de la familia del empresario al Instituto de Investigaciones Gino Germani, FSOC-UBA. Las secuencias analizadas están divididas en tres partes, con una duración de 27:25 las dos primeras y 3:58 la última, reuniendo 58 minutos en total.

12 El acta establece que la adjudicación de la licencia se realizó según el decreto 2776 del 25 de octubre de 1983 y a los fines de lo previsto del art. 33 incisos B y E y en el anexo segundo de las bases y condiciones del concurso aprobado por decreto 462 de 1981 y resolución del COMFER 601 de 1982.

13 Según el tiempo de conteo del archivo que guarda estas imágenes, cuando el escribano da por finalizada la entrega, han transcurrido un poco más de cuatro minutos, sin embargo, según el texto leído por el letrado, habían pasado 40 minutos desde el inicio.

14 Con respecto a la situación económica, el informe de Garrido señala que la pérdida a diciembre de 1983 era de 85 millones de pesos. Recién en el mes de marzo de 1984 empezó a vislumbrarse un cambio, detalla facturaciones de febrero a mayo, y proyecta la facturación de los dos meses siguientes con números muy auspiciosos; las entradas y las salidas estarán equiparadas para el mes de agosto, momento en que el canal podría solventar inversiones para renovar su equipamiento.

15 Datos de elaboración propia en función de la base de datos de programación televisiva elaborada en el marco del Proyecto Ubacyt20020130100192BA Televisión, dictadura y transición en América Latina: un estudio comparado, Programación 2014-2017, dirigido por Mirta Varela. 